\title{
A Comparison Study between the Newly Developed Vertical Wells Steam Assisted Gravity Drainage and the Conventional SAGD Process
}

\author{
M. Shirif, A. Alarbah, H. Ibrahim, E. Shirif* \\ Faculty of Engineering, University of Regina, Regina, Canada \\ Email: *ezeddin.shirif@uregina.ca
}

How to cite this paper: Shirif, M., Alarbah, A., Ibrahim, H. and Shirif, E. (2017) A Comparison Study between the Newly Developed Vertical Wells Steam Assisted Gravity Drainage and the Conventional SAGD Process. Engineering, 9, 575-590. https://doi.org/10.4236/eng.2017.96036

Received: April 21, 2017

Accepted: June 26, 2017

Published: June 29, 2017

Copyright ( 92017 by authors and Scientific Research Publishing Inc. This work is licensed under the Creative Commons Attribution International License (CC BY 4.0).

http://creativecommons.org/licenses/by/4.0/ (c) (i) Open Access

\begin{abstract}
A numerical simulation study using the CMG-STAR Simulator was performed to compare the performance of the newly developed process (VWSAGD) utilizing vertical wells to enhance heavy oil recovery during steam assisted gravity drainage against the conventional steam assisted gravity drainage process which utilized horizontal wells (HWSAGD) under the same operating conditions. Two identical reservoir models were simulated for the two processes using 3-Dimensional, black heavy oil model ( $14^{\circ}$ API). Each reservoir type consists of $49 \times 49 \times 20$ grid blocks on a 5-acre model, which incorporated a typical heavy oil reservoir rock and fluid properties taken from the SPE case study, stspe001.dat (CMG 2015 release). A sensitivity analysis for both processes was performed for the grid density, soaking time, steam quality, bottom hole producing pressure, steam injection rate, reservoir thickness, reservoir area, and horizontal to vertical permeability anisotropy. More preferable reservoir conditions are those such as high horizontal to vertical permeability ratio, thick reservoir oil zones, as well as improved reservoir recovery for the VWSAGD process. Under unfavorable conditions such as thin reservoir oil zones, an improved reservoir recovery response was limited for the VWSAGD process and could be uneconomical in real field cases. Finally, the simulation results from this study include cumulative recoveries, Steam oil ratios, produced water-oil ratios, pressure and temperature distributions, and production rates. In addition, the results from this study have shown that the new VWSAGD process is more favorable than the conventional HWSAGD process.
\end{abstract}

\section{Keywords}

Ertical Wells Steam Assisted Gravity Drainage, Conventional SAGD Process 


\section{Introduction}

Over the past four decades, the conventional hydrocarbon reserves have declined rapidly. With an increase in the number of oil fields reaching economic limits and nearing maturity, new EOR recovery options are needed for reservoirs that are more challenging to produce, particularly heavy oil reservoirs and bitumen. Heavy oil reservoirs contain a large amount of petroleum resources that have not yet been fully utilized. In Canada alone, it is estimated that there are over 750 billion barrels of heavy oil. The efficiency and economic recovery of heavy oil and bitumen deposits from these oil reservoirs are a major technical challenge.

Steam injection technology has been used for many decades to improve the recovery of heavy oil. The main mechanism during steam injection is the reduction of oil viscosity and residual oil saturation by increasing the reservoir temperature. Effective methods are required in order to produce the heavy oil. A potential option for this is by the use of steam assisted gravity drainage (SAGD) and cyclic steam stimulation (CSS).

Butler in the 1980's developed conventional Steam Assisted Gravity Drainage known as SAGD. SAGD maximizes gravitational forces during the steam flooding of heavy oils. Typically, a pair of parallel horizontal wells is used. As steam is injected into the reservoir, it heats up the reservoir oils, and the adjacent rock. The heated oil and condensed water will flow downward by force of gravity towards the producing horizontal well at the bottom of the formation. In conventional SAGD, the steam is injected through a horizontal well, which is placed directly above a horizontal producer. This causes a steam zone (chamber) to form around the injection well. After the heat-up period for HWSAGD is initiated, a steam chamber will form and grow upward towards the top of the reservoir and begin to expand/enlarge horizontally [1] [2]. At the steam chamber boundary, steam is condensed as heat is transferred to the surrounding oil. The heated oil and condensed water flow down along the steam chamber boundary towards the production horizontal well [1] [2].

In the conventional cyclic steam stimulation process (CSS), a single vertical well is completed across the entire thickness of a heavy oil reservoir. Steam is then injected, and oil and condensed water are produced in cycles from the same vertical well. Each of the cycles contains three different stages; injection, soaking, and production period. During the injection period, which lasts for approximately fifteen days, steam is injected at a constant rate or at a constant pressure, which forms a steam zone (chamber) around the area of the wellbore in the reservoir, which grows outwards from the well. This causes a significant reduction of the oil viscosity in the steam zone. The well is then shut in order to allow the adjacent oil to be heated beyond the steam zone by heat conduction from the steam zone. The heat transfer from the steam zone as well as the heat loss to the neighboring formation (over-burden and under-burden) causes a decrease in the steam zone temperature. Having too low of a steam zone temperature causes issues, so to avoid this; the soaking period is usually restricted to around seven days. After the soaking periods, the vertical well is then opened to production. 
Depending on what type of reservoir rock formation, as well as the reservoir fluid properties, the production period usually lasts for several months [3]. Each steam injection cycle causes the steam zone to increase, and for more heat to be lost to the over burden and under burden, resulting in a decrease in the thermal efficiency of the CSS process. In addition, the average reservoir pressure continues to decline due to the production of the heated oil and the condensed steam injected. As a result, the ultimate oil production rate continues to decline with every steam cycle until an economic limit is reached. Normally, cyclic steam stimulation has a maximum recovery of approximately $15 \%-20 \%$ of the initial oil-in-place (IOIP) of the well-drained area.

The newly developed Vertical Well Steam Assisted Gravity Drainage Process (VWSAGD) optimizes the role of gravitational forces, viscosity reduction, and viscous forces during the steam flooding of heavy oils. It is usually applied with a single vertical well. The VWSAGD process is a similar concept to both the conventional SAGD and CSS process. As steam is injected into the reservoir, it causes the reservoir fluids and surrounding rock adjacent to the wellbore to heat up, which allows hot oil and condensed water to flow and drain through by gravitational and viscous forces to a single vertical injection/production well located at the bottom of the formation. For VWSAGD process, heat is transferred into the reservoir by conduction and convection.

\section{Problem Statement}

This research study is grouped into four general topics:

I. Assessment of the newly development Steam Assisted Gravity Drainage process that employs vertical wells (VWSAGD). Graphic representation of the new Vertical Well Steam Assisted Gravity Drainage Process is shown in Figure 1.

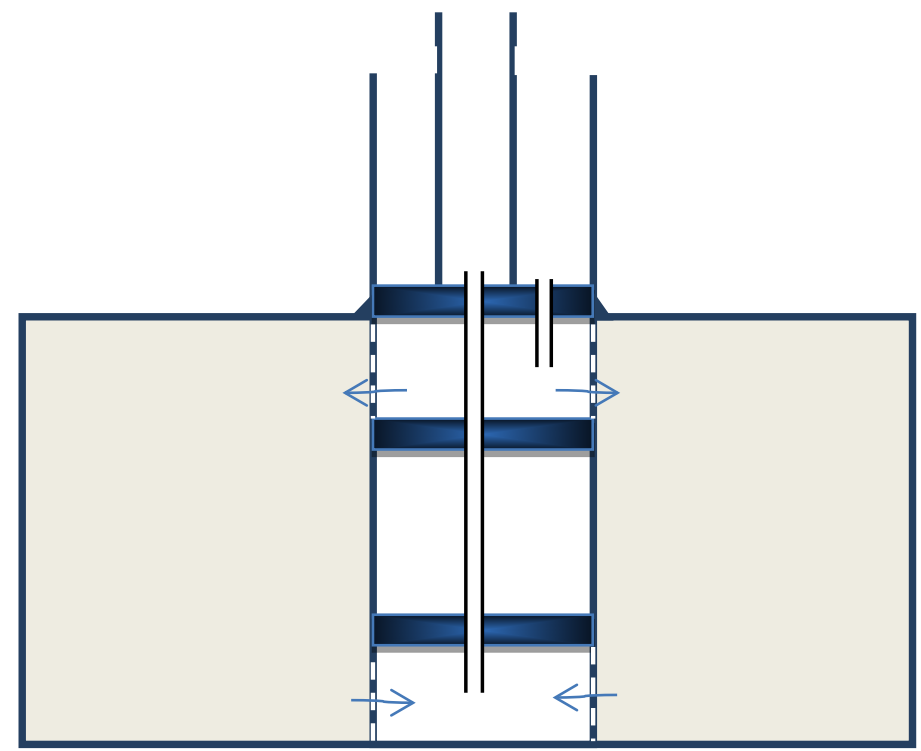

Figure 1. Schematic of vertical well steam assisted gravity drainage process. 
II. Optimization study to evaluate the applicability and the accuracy of VWSAGD process.

III. A sensitivity analysis on the effect of reservoir rock and fluid and well completion parameters for VWSAGD and conventional HWSAGD.

IV. A sensitivity analysis on the effect of reservoir rock and fluid and well completion parameters on conventional HWSAGD.

Familiarity and knowledge of the well operating conditions for the VWSAGD process for optimization and performance improvement is directly related to understanding methods of thermal recoveries such as CSS and SAGD. The sensitivity analysis assists to identify reservoir properties, fluid conditions, and well completion strategies where the new process (VWSAGD) may be a suitable EOR thermal process.

\section{Motivation}

Steam injection technology has been used for many decades to improve the recovery of heavy oil. The main mechanism during steam injection is the reduction of oil viscosity and residual oil saturation by increasing the reservoir temperature. SAGD technology is very expensive because of the high cost of drilling horizontal wells, high operating cost, as well as the recent decline in oil prices.

The conventional steam assisted gravity drainage process (HWSAGD) utilizes a pair of parallel horizontal wells (injector and producer well). These horizontal wells have a much greater contact area with the reservoir than that of conventional wells. There are major potential problems and limitations besides the high operating costs when considering HWSAGD projects. The reservoir limiting parameters which make the HWSAGD process unattractive are [1] [4] [5]: reservoir thickness under $40 \mathrm{ft}$; vertical permeability less than $3000 \mathrm{md}$; high areal and vertical reservoir heterogeneity; poor reservoir quality; high initial water saturations and low oil saturation; reservoirs containing a large gas-cap and/or strong bottom water zone; reservoir operating pressure less than 150 psia; inadequate lifting capacity and steam chamber unable to be drawn down particularly with very long wells; steam chamber pressure is too low to prevent water intrusion; production of high hot water oil ratio; numerous changes in the operating conditions causing management of horizontal well SAGD projects to be very labor intensive and decline of production in later stages.

\section{Objectives}

The conventional Steam Assisted Gravity Drainage (HWSAGD) using horizontal wells is a very expensive process to implement due to the high cost of drilling two horizontal wells as well as the operating cost associated with this process. In contrast, the cost of drilling and operating a vertical well is relatively inexpensive compared to horizontal well. Therefore, the main objective of this study is to test the applicability of the newly develop Steam Assisted Gravity Drainage process utilizing vertical wells. 


\section{Methodology}

To assess the applicability of the newly developed process, we built and compared various simulation runs for VWSAGD and conventional HWSAGD processes. For the sensitivity analysis, a base case model run was compared against other runs where we varied the grid density, soaking time, steam quality, steam injection rate, bottom hole flowing pressure, reservoir height, reservoir area, permeability anisotropy, as well as the well completion. To achieve the stated objective, Computer Modeling Group's (CMG) STARS Thermal Simulator was used to perform all tasks proposed in this study.

\section{Description of the Numerical Model}

The numerical model data used for this study is based on CMG's STARS release 2015 case study, stspe001.dat. The reservoir rock and fluid properties as well as the thermal properties of rock/fluids represent a typical heavy oil reservoir of Lloydminster in Alberta, Canada. The CMG's stspe001.dat case study is a 2-D-radial model used for simulating the CSS process. The reservoir radial geometry was converted to a 3-D Cartesian model in order to simulate the horizontal and vertical wells. The well operating conditions and well completion were also modified substantially to develop additional cases for HWSAGD and VWSAGD processes. The grid system and dimensions for simulating the VWSAGD process is shown in Figure 2. The grid system and dimensions for simulating the HWSAGD process is illustrated in Figure 3. Both grid systems are 3-D Cartesian with local grid refinement around the wellbore.

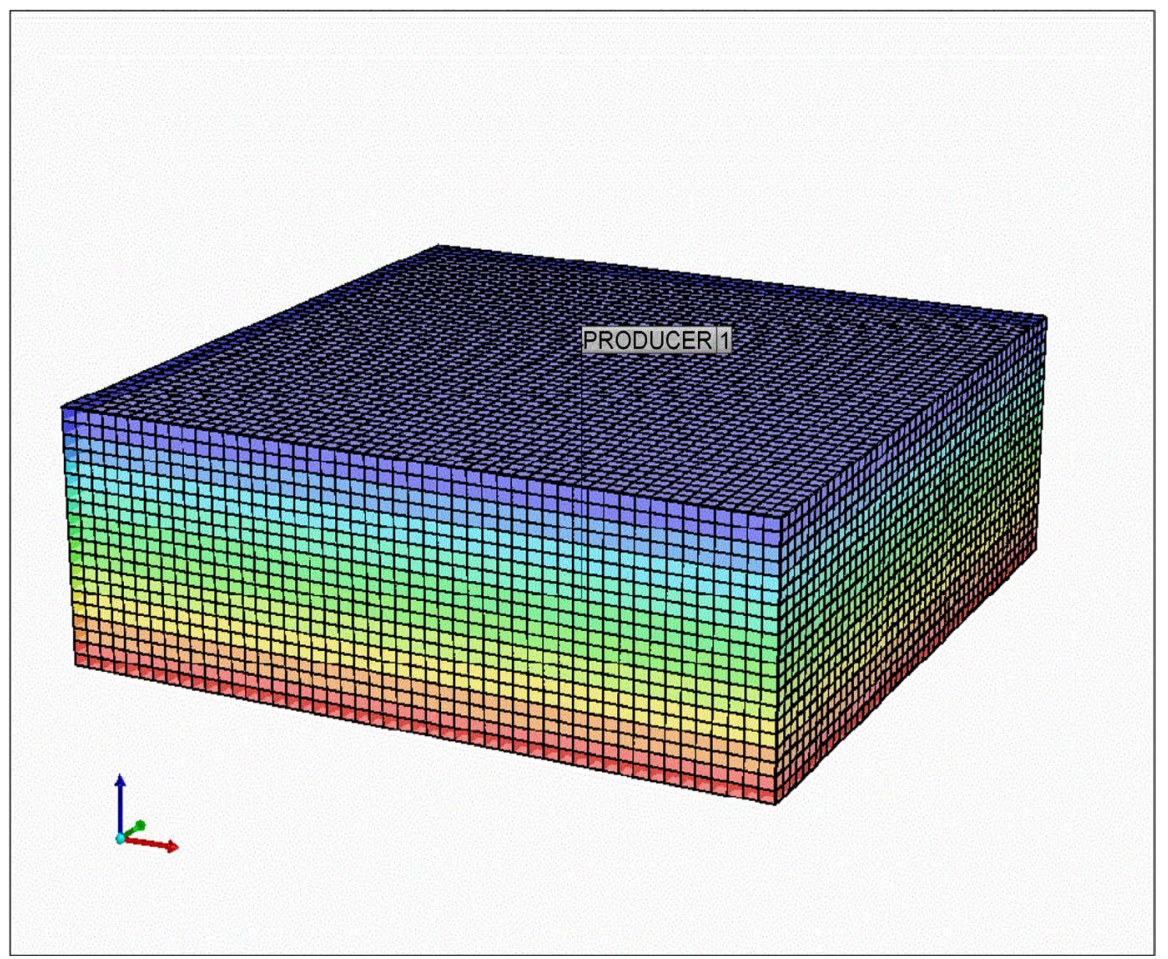

Figure 2. 3-D cartesian model grid system for simulating VWSAGD process. 


\section{Reservoir Properties}

The relevant reservoir property data are taken from CMG's stspe001.dat case study. A summary of the reservoir model properties for all Runs are shown in Table 1.

\section{Relative Permeability}

The reservoir model used is a water-wet sandstone media. The relative permeability data which were used in this study are based on the CMG stspe011.dat case

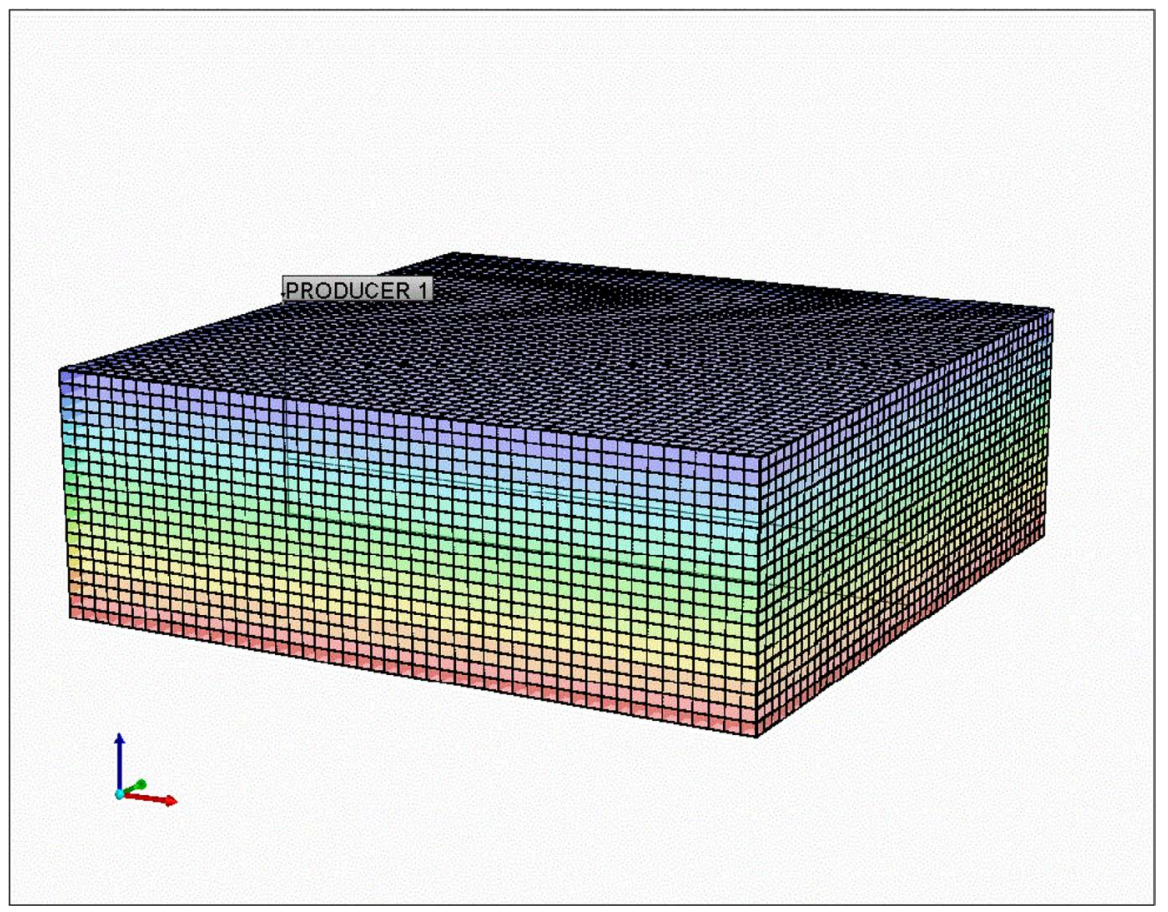

Figure 3. 3-D cartesian model grid system for simulating HWSAGD process.

Table 1. Reservoir physical properties.

$\begin{array}{cc}\text { Reservoir area, (Acre) } & 5-30 \\ \text { Reservoir thickness, (ft) } & 20-200 \\ \text { Initial oil saturation, (\%) } & 55 \\ \text { Reservoir porosity, (\%) } & 30 \\ \text { Initial water saturation, (\%) } & 40 \\ \text { Initial reservoir pressure, (psia) } & 17 \\ \text { Initial reservoir temperature, }\left({ }^{\circ} \mathrm{F}\right) & 120 \\ \text { Vertical permeability, (md) } & 100-1500 \\ \text { Horizontal permeability, (md) } & 1000 \\ \text { Oil viscosity at SC, (cp) } & 5780 \\ \text { Oil molecular weight } & 600 \\ \text { Oil mass density, }(\mathrm{lb} / \mathrm{cf}) & 60.678 \\ \text { Standard pressure, }(\mathrm{psia}) & 14.7 \\ \text { Standard temperature, }\left({ }^{\circ} \mathrm{F}\right) & 60 \\ \text { Formation compressibility, }(1 / \mathrm{psia}) & 5 \times 10^{-4}\end{array}$


study. The relative permeability is generated using correlations proposed by Honarpour et al. (1986) [6]. The two-phase water oil relative permeability as a function of water saturation and the two-phase gas oil relative permeability as a function of oil saturation are shown in Figure 4 and Figure 5 respectively. The three phase relative permeability was generated using Stone's model.

\section{Heavy Oil Viscosity Model}

The oil viscosity used for this study is generated by the experimental method. The dependence of oil viscosity on temperature is shown in Figure 6.

\section{Base Model}

The 3D-Cartesian grid base model for VWSAGD and HWSAGD processes has dimensions $49 \times 49 \times 20$. The total number of grid blocks is 49,020 . The reservoir base model is homogenous with a single porosity of $30 \%$, horizontal permeability $\left(\mathrm{k}_{\mathrm{H}}=\mathrm{k}_{\mathrm{x}}=\mathrm{k}_{\mathrm{y}}\right)$ of $1500 \mathrm{md}$, and vertical permeability of $500 \mathrm{md}$. The connate water saturation is $45 \%$, and initial oil saturation is $55 \%$. Initial oil in

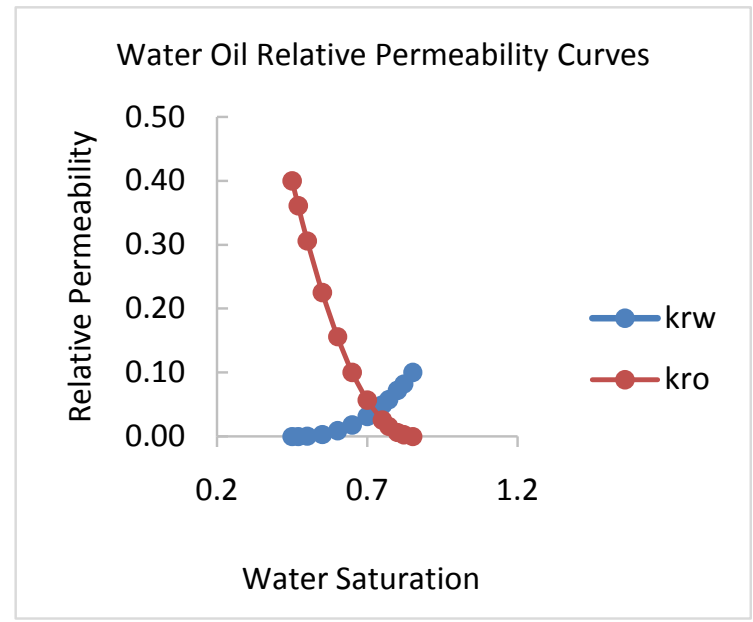

Figure 4. Two-phase water oil relative permeability.

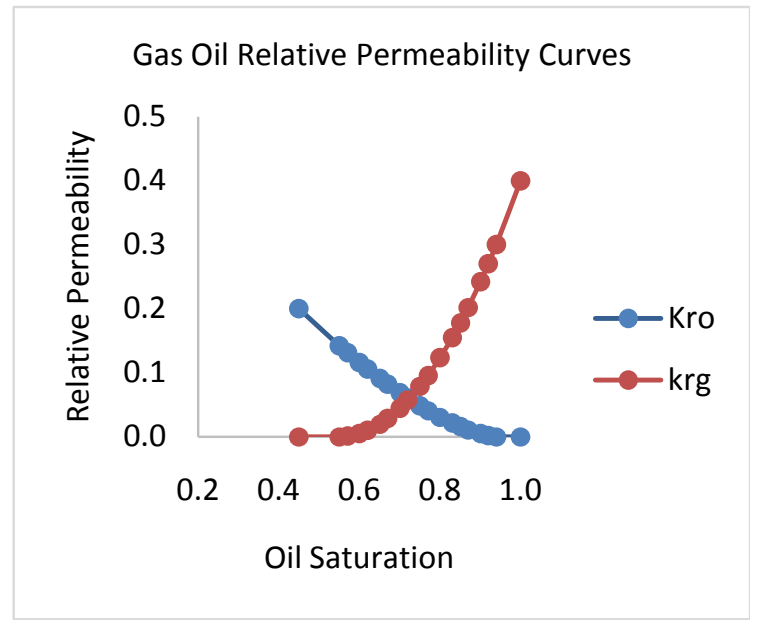

Figure 5. Two-phase gas oil relative permeability. 
place is $2,897,500 \mathrm{ft}^{3}(516,028 \mathrm{bbl})$, initial reservoir pressure of $75 \mathrm{psia}$, and a temperature of $125^{\circ} \mathrm{F}$. The dead oil density and viscosity are approximately $60.678 \mathrm{lb} / \mathrm{cf}$ and $5780 \mathrm{cp}$ respectively. The base model operating conditions and other relevant parameters are listed in Table 2.

\section{Well Data}

For the HWSAGD process, the two parallel horizontal wells go through the entire reservoir in the $\mathrm{x}$-direction. The two well placed in the center of reservoir model. The horizontal producer is placed four feet from the bottom. The horizontal injector is placed $15 \mathrm{ft}$ above the horizontal producer.

For the VWSAGD process, the single vertical well is located at the center of the reservoir $(25,25$, and 1$)$ and goes through the entire reservoir thickness. The short injection string (SIS) is assigned at top quarter of the perforation and the long production string (LPS) is assigned at bottom quarter of the perforation. For both processes, a five-year simulation time was chosen for all of the runs. The simulation starts at 2015-01-01 and finishes at 2021-1-1. Before the start of the simulation period for the base models, a period of 20 days was selected as the duration of the startup period flowed by 10 days as the soak period. The reservoir temperature distributions at the end of simulation time for both processes are shown in Figure 7 and Figure 8.

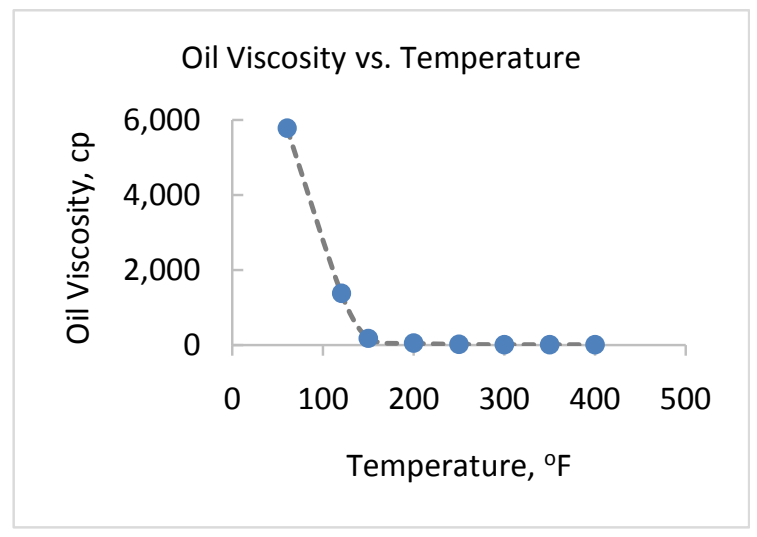

Figure 6. Dependence of dead oil viscosity on temperature.

Table 2. Base model properties description.

$\begin{array}{cc}\text { Reservoir area, (Acre) } & 5 \\ \text { Reservoir Thickness, (ft) } & 80 \\ \text { Vertical permeability, (md) } & 500 \\ \text { Horizontal permeability, (md) } & 1000 \\ \text { Initial reservoir pressure, (psia) } & 75 \\ \text { Steam quality } & 0.7 \\ \text { Steam injection rate, (cwe), (bbl/day) } & 1000 \\ \text { Maximum steam injection pressure, (psia) } & 1000 \\ \text { inimum bottom hole producing pressure, (psia) } & 17\end{array}$




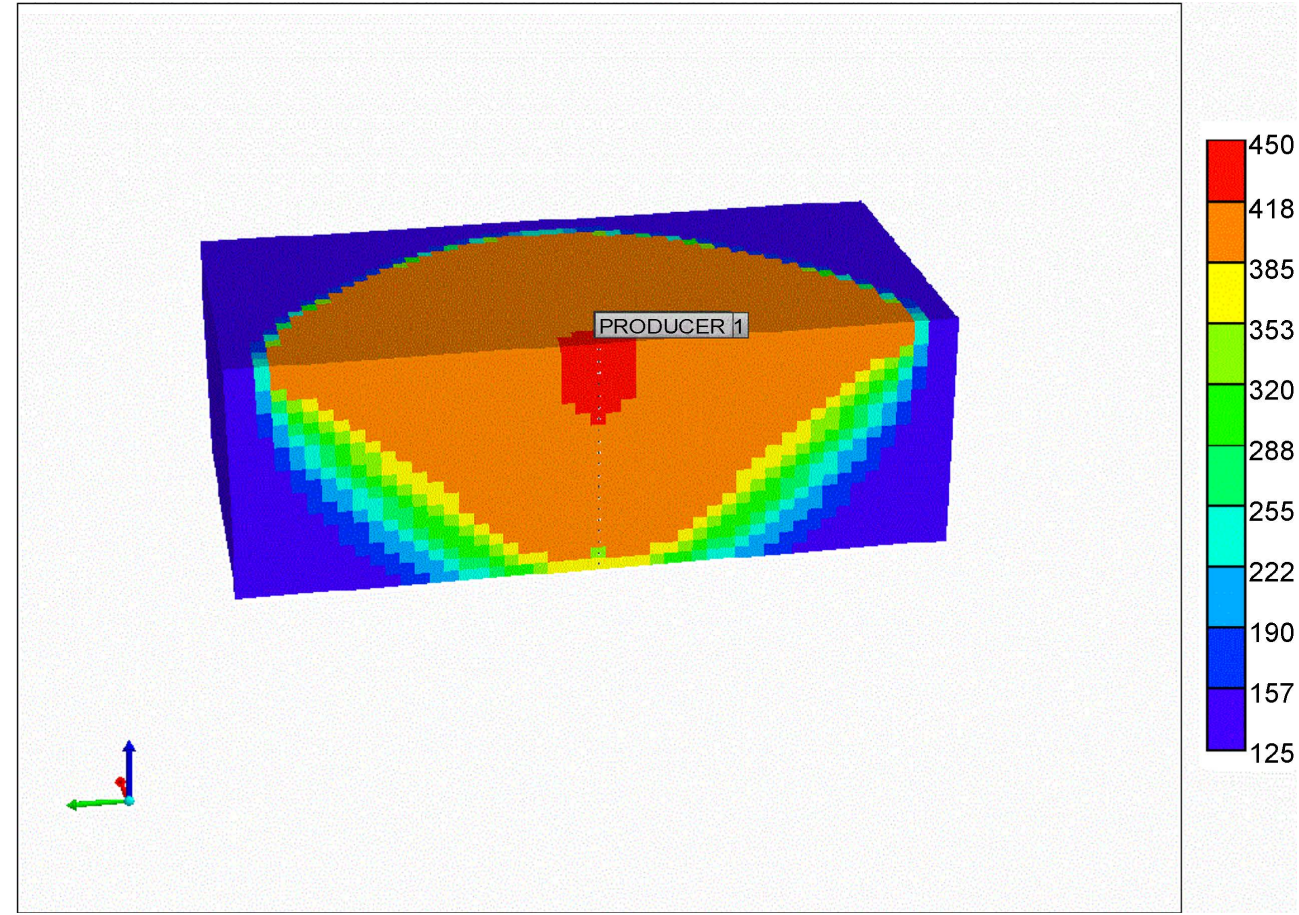

Figure 7. VWSAGD temperature distribution at end of simulation time.

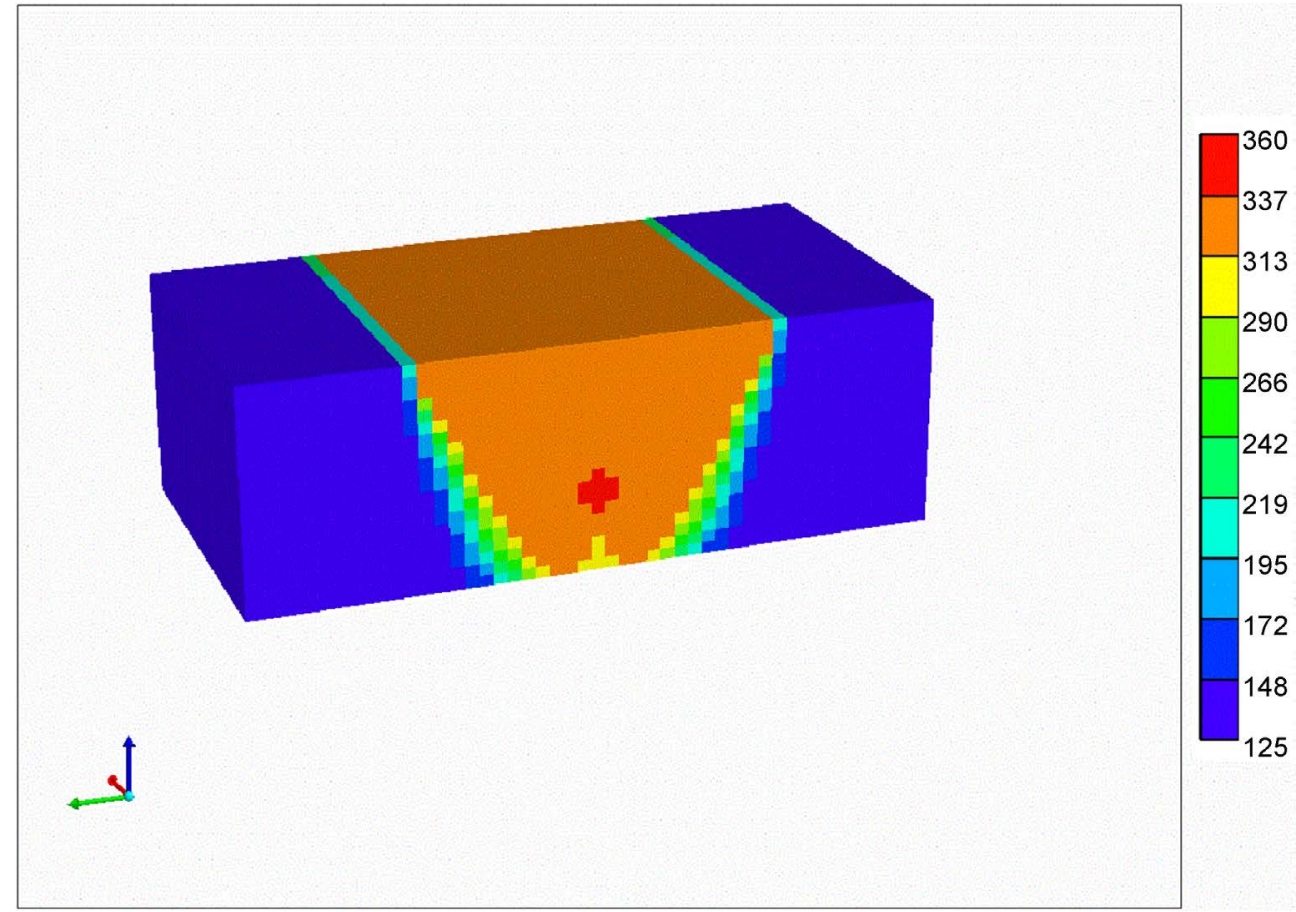

Figure 8. HWSAGD temperature distribution at end of simulation time.

\section{Results and Discussion}

In this study, the newly developed vertical Well SAGD process has been optimized and tested. The results from this process were compared to the conventional SAGD process, which uses horizontal wells. A sensitivity study was conducted to study the effect of the vertical permeability, reservoir area size, reser- 
voir thickness, steam injection rate, steam quality, producing bottom hole flowing pressure, and the steam injection pressure. In addition, a comparison between the VWSAGD and conventional HWSAGD processes was made.

Optimization of the Grid Density

When dealing with numerical reservoir simulators, special attention must be given to the number of grid blocks used to simulate the entire reservoir. A small number of reservoir grids will result in a higher truncation error. A higher number of reservoir grids will cause a decrease in the truncation error, and at the same time, the round off error will increase. In the commercial simulator used for this study, there was an option to choose the method of solution of the finite difference equation using iterative techniques (round off error will not accumulate). For this study, we selected and simulated five grid sizes. Based on the simulation results, it is clear that the optimum grid size is $49 \times 49 \times 20$.

\section{Optimization of Reservoir Perforation}

For the base run in this study, the reservoir thickness was selected to be $80 \mathrm{ft}$, and the question posed was what is the optimum perforation zone for the short injection string, and the long production string. In order for us to optimize the perforation of the two strings, 23 simulation runs were conducted to calculate the optimum intervals, which will give us the lowest steam oil ratio, lowest water oil ratio and maximum cumulative oil recovery. Based on the simulation results of this study, it has been found that perforating the top quarter of the reservoir for the short injection string, and the bottom quarter of the reservoir for the long production string were the optimum perforations.

\section{Comparison of VWSAGD and HWSAGD}

Steam Assisted Gravity Drainage using horizontal wells is an extremely expensive process to implement due to the high cost of drilling two horizontal wells as the operating cost associated with this process. In contrast, the newly developed vertical well SAGD process requires only a single vertical well and is inexpensive to drill, and a low operation cost compared as compared to horizontal wells. Based on a literature review, the cost of drilling an operating horizontal well is 5 - 6 times more expensive than a vertical well, and sometimes it costs more if the horizontal well increases in length. In order for us to compare the productivity of the two processes, we have made a very conservative assumption that the cost of drilling and operating a horizontal is equal to two vertical wells. This means drilling a pair of horizontal wells for conventional SAGD is equivalent to developing the same reservoir with four vertical wells. Each area pattern must be divided into four equal sections, and each quarter section will be developed by a single vertical SAGD well. For the well operating conditions, the steam injection rate must be reduced by one quarter for each section. The total production of the entire drainage area will equal to four times the production of a quarter section. This allows us to only simulate quarter sections of the reservoir by a single vertical well, and is then compared to horizontal well SAGD. Figures 9-20 show the production history for one single quarter section area developed by vertical well SAGD. Figure 9 shows the cumulative recovery as a 


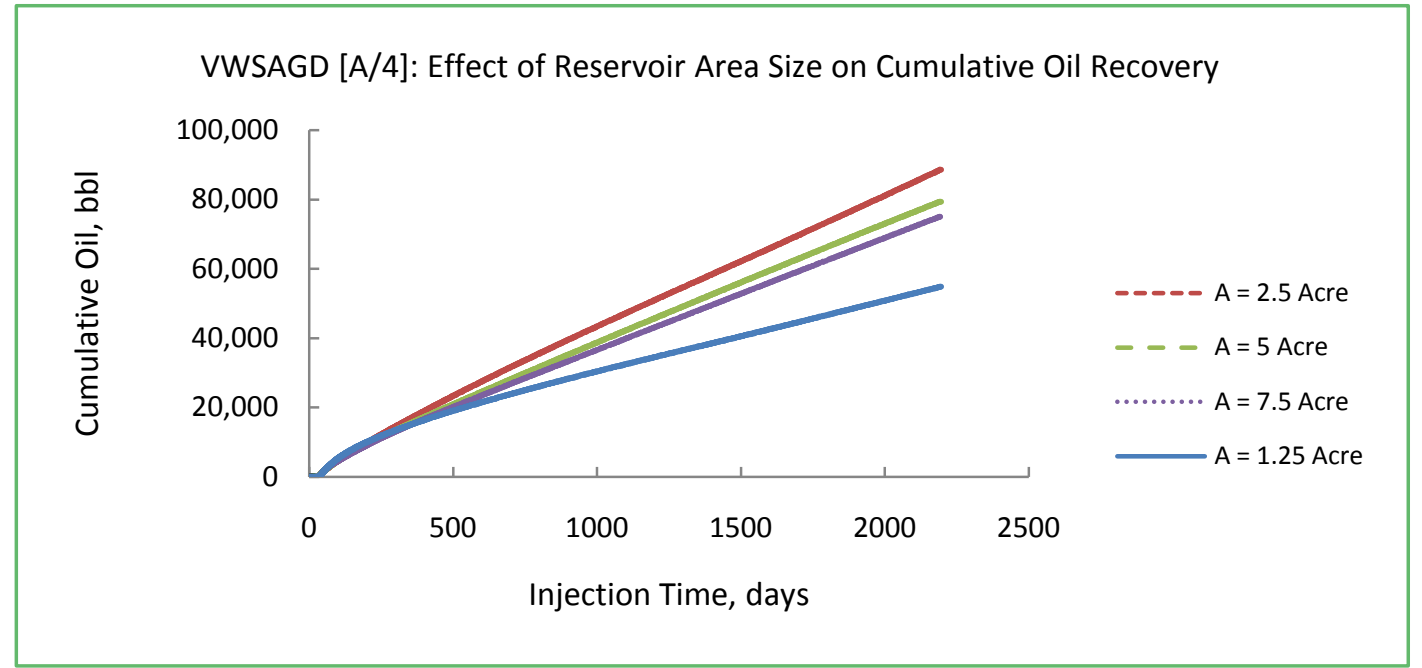

Figure 9. Effect of quarter section areas on cumulative oil recovery for VWSAGD process.

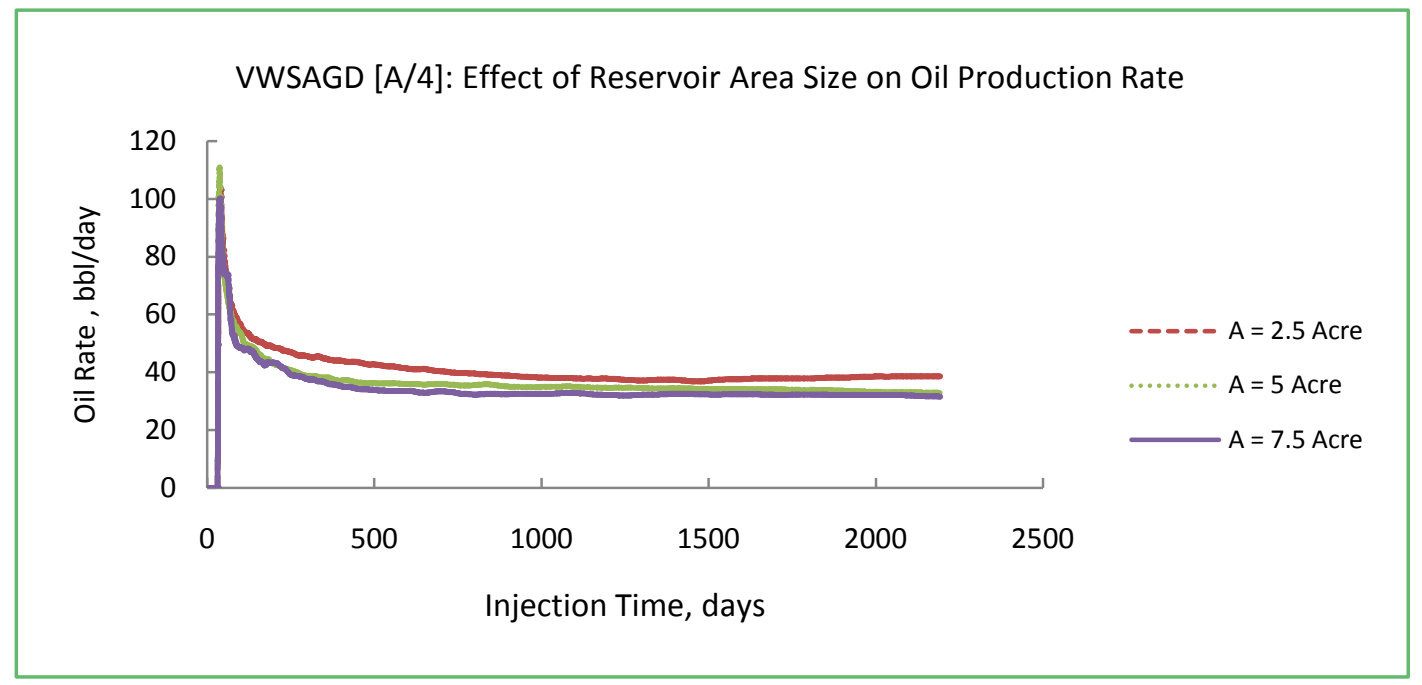

Figure 10. Effect of quarter section areas on oil production rate for VWSAGD process.

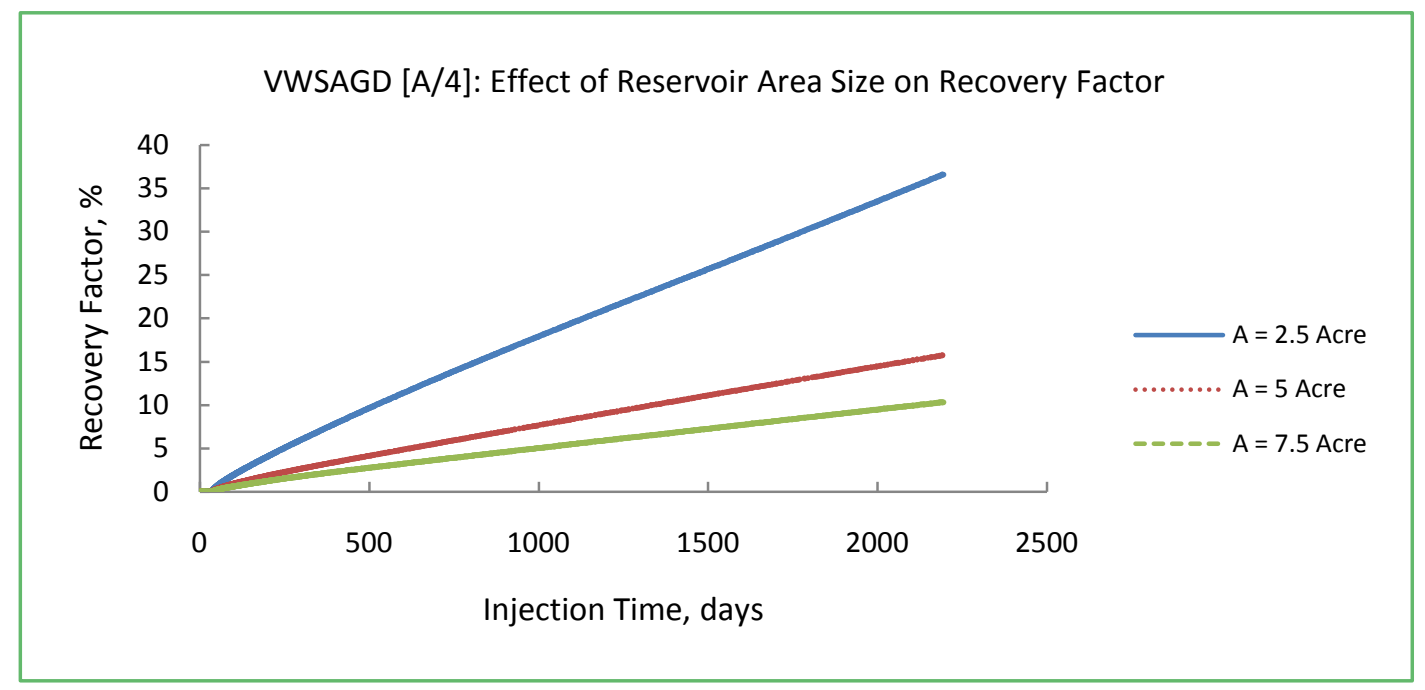

Figure 11. Effect of quarter section areas on recovery factor for VWSAGD process. 
function of the quarter section area. It is clear that as the area increases, the cumulative recovery decreases. This is due to the fact that a limited steam injection will heat up the entire small area of the reservoir and a result; this will produce a higher oil recovery. This conclusion is also supported by the results presented in Figures 10-13. The smallest section area (2.5 acres) gave the highest oil rate, lowest steam oil ratio, lowest water oil ratio, and the highest oil recovery. If we examine the cumulative oil recovery in Figure 9, the section area (1.25 acres) gave the lowest oil recovery, which contradicts the conclusion made earlier. The justification for this low recovery is shown in Figure 14. The smallest area (1.25 acres) was unable to sustain an injection rate of $250 \mathrm{bbl} /$ day of steam. Meanwhile, the other three areas (2.55 acres, 7.5 acres) showed no problem of sustaining a steam injection rate of $250 \mathrm{bbl} /$ day. The smallest received only $25 \%$ of the amount of steam injected compared to the other three areas. This is the reason why this area gave the smallest recovery. Figure 15 shows that the average pressure for the smallest area was the highest, and Figure 16 shows the average

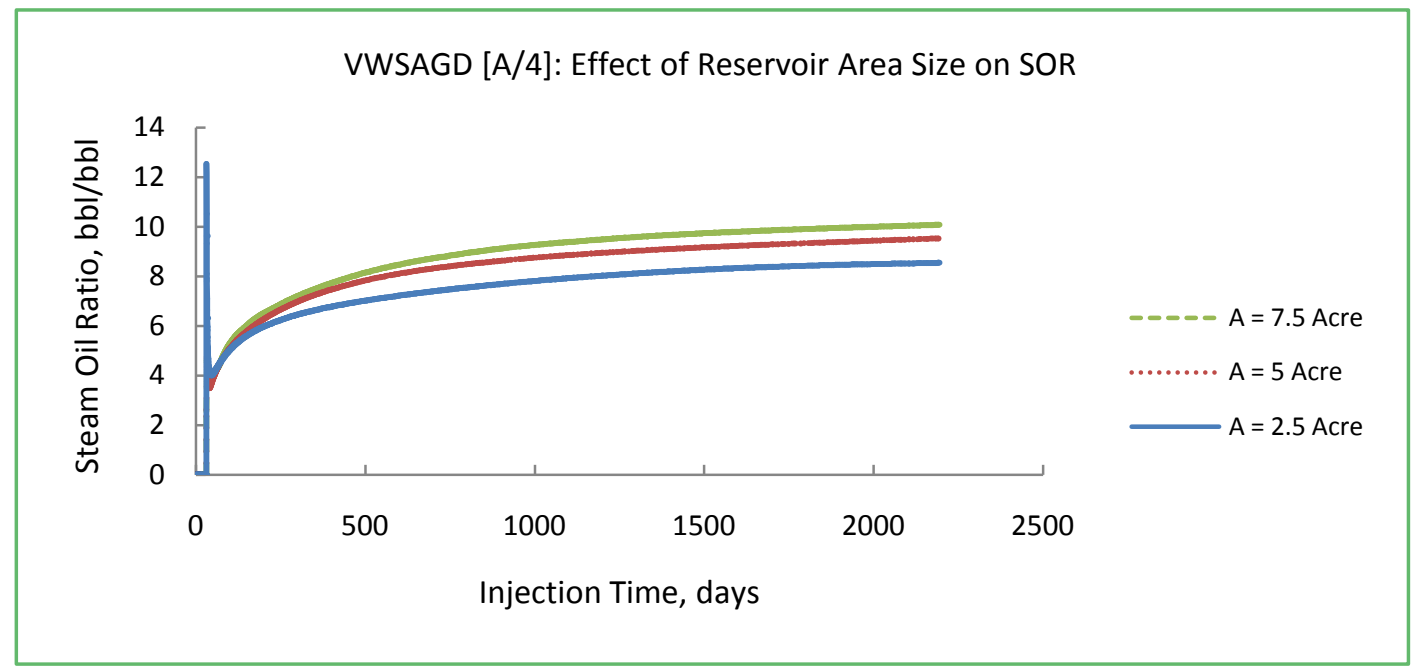

Figure 12. Effect of quarter section areas on steam oil ratio vertical well SAGD process.

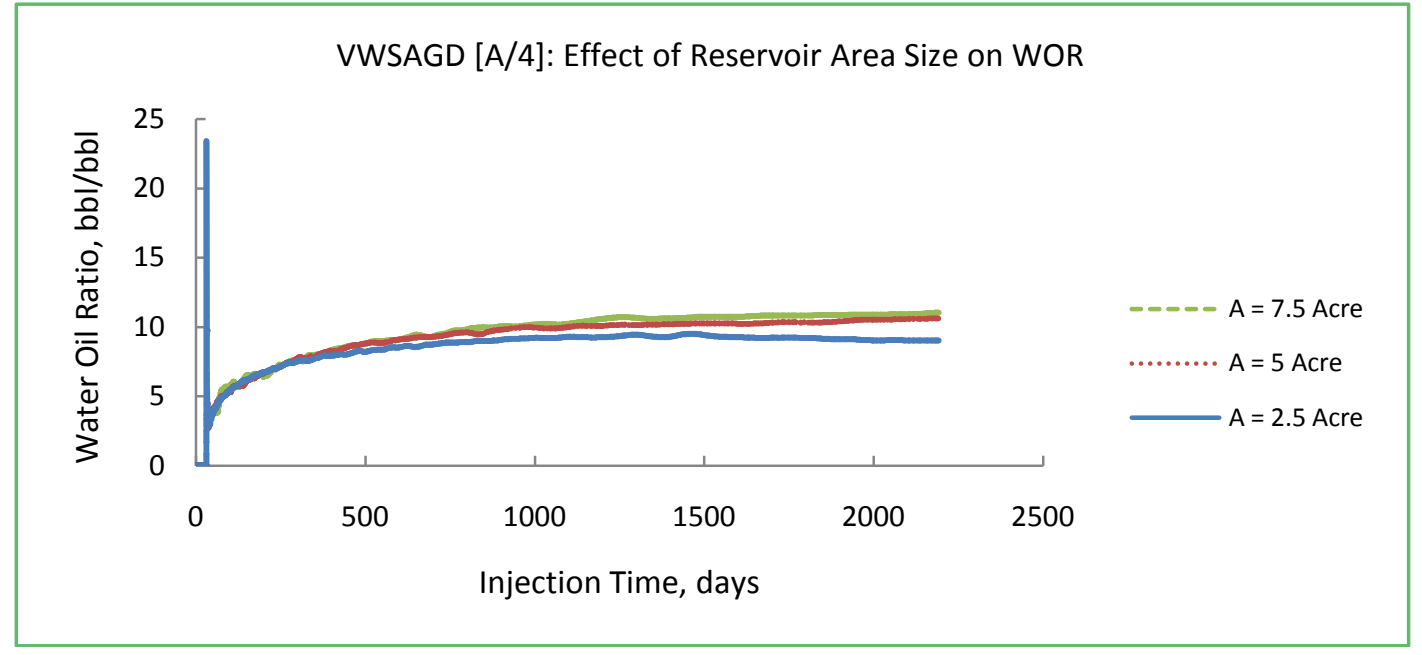

Figure 13. Effect of quarter section areas on water oil ratio for VWSAGD process. 


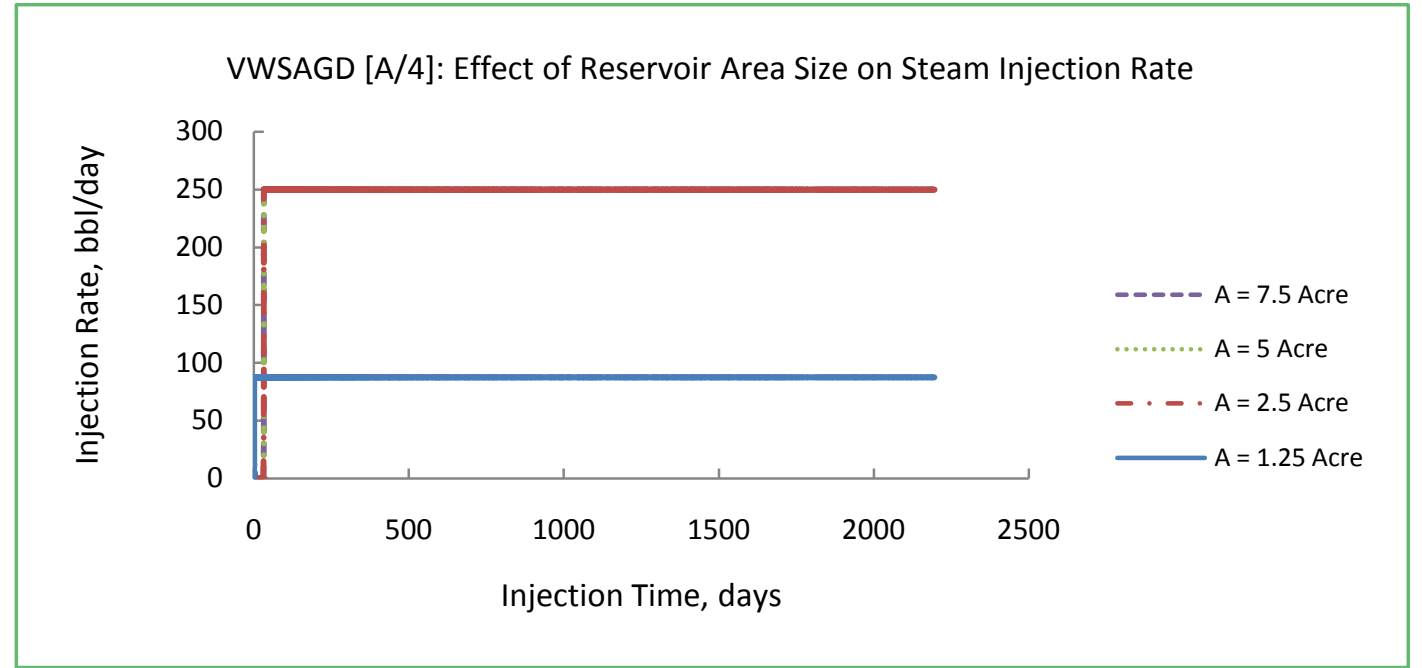

Figure 14. Effect of quarter section areas on steam injection rate for VWSAGD process.

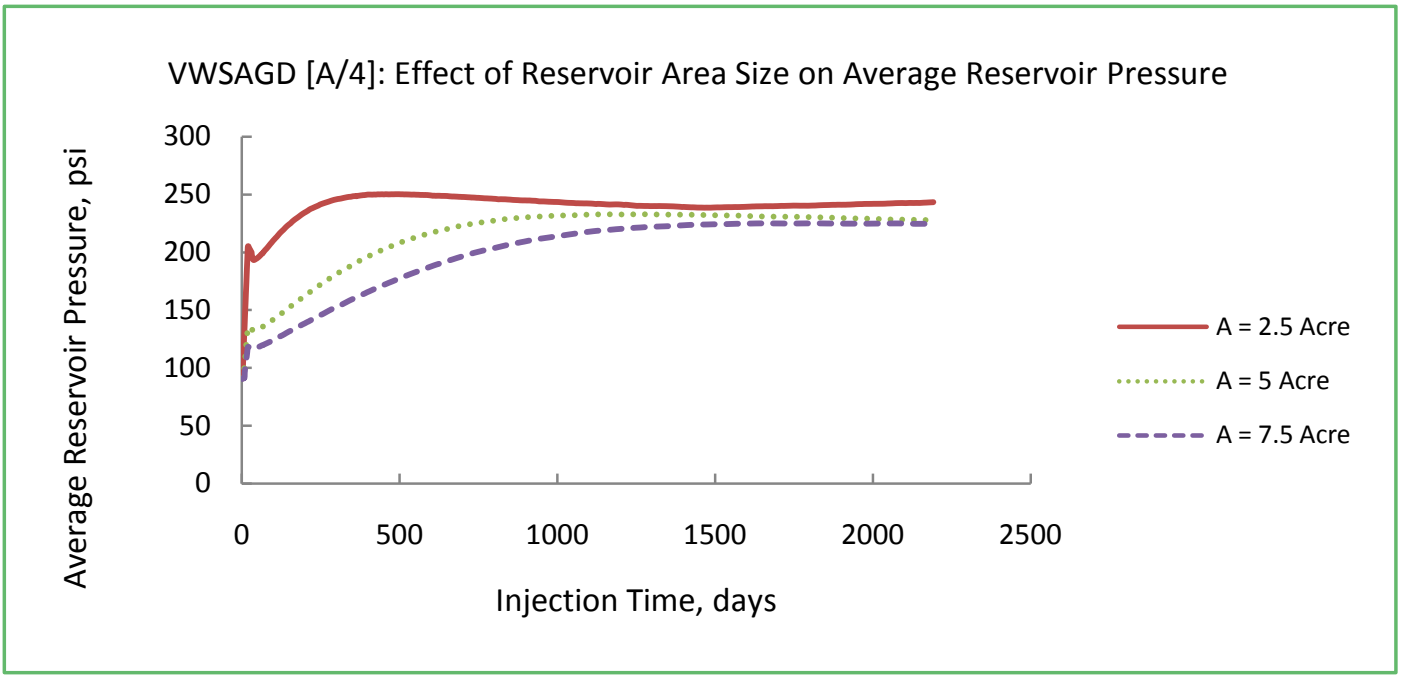

Figure 15. Effect of quarter section areas on average reservoir pressure for VWSAGD process.

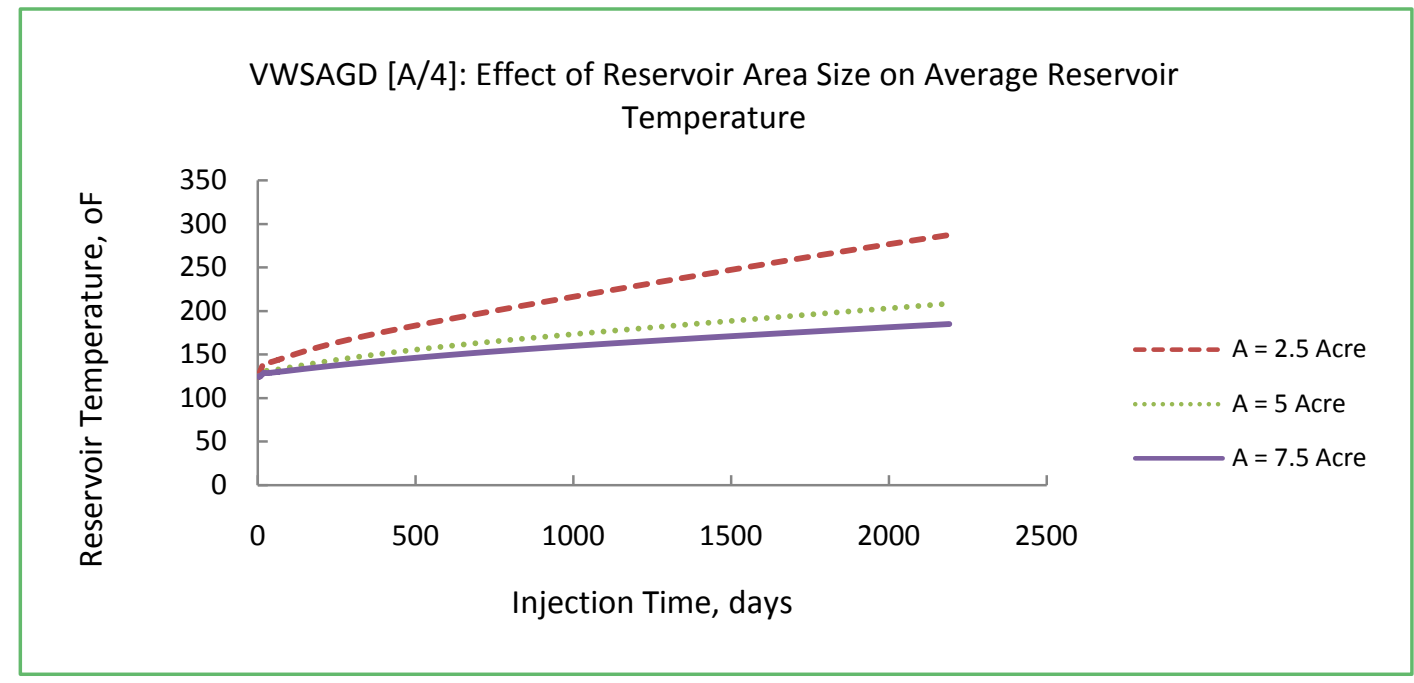

Figure 16. Effect of quarter section areas on reservoir temperature for VWSAGD process. 
temperature was the highest for the smallest area. These two results support the previous finding. Figure 17 shows the effect of quarter section areas on cumulative liquid production for VWSAGD process.

Figure 18 shows the effect of the area size on the cumulative oil recovery produced by the four vertical well SAGD process. The results obtained for the single vertical well were multiplied by four. To show the comparison between the newly developed process and the conventional SAGD process, the results are shown in Figure 19 and Figure 20. In Figure 19, the effect of reservoir thickness on the cumulative oil recovery when produced by single vertical well SAGD, four vertical well SAGD, and the paired horizontal well SAGD. The results show that the four vertical well SAGD outperformed the horizontal pair SAGD by a large amount. When the area reached 30 acres, both of these processes gave the same results. Figure 20 shows the effect of the reservoir area on the cumulative oil recovery produced by the three processes. The results show that as the area

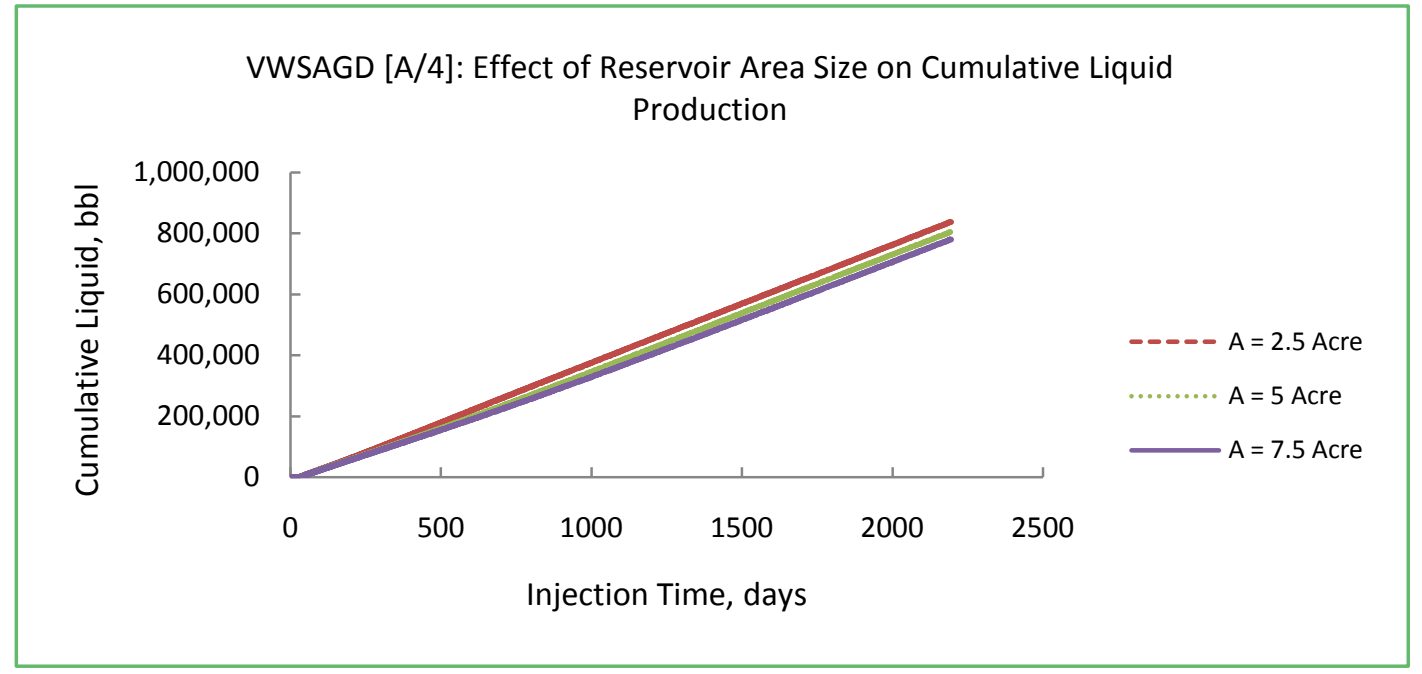

Figure 17. Effect of quarter section areas on cumulative liquid production for VWSAGD process.

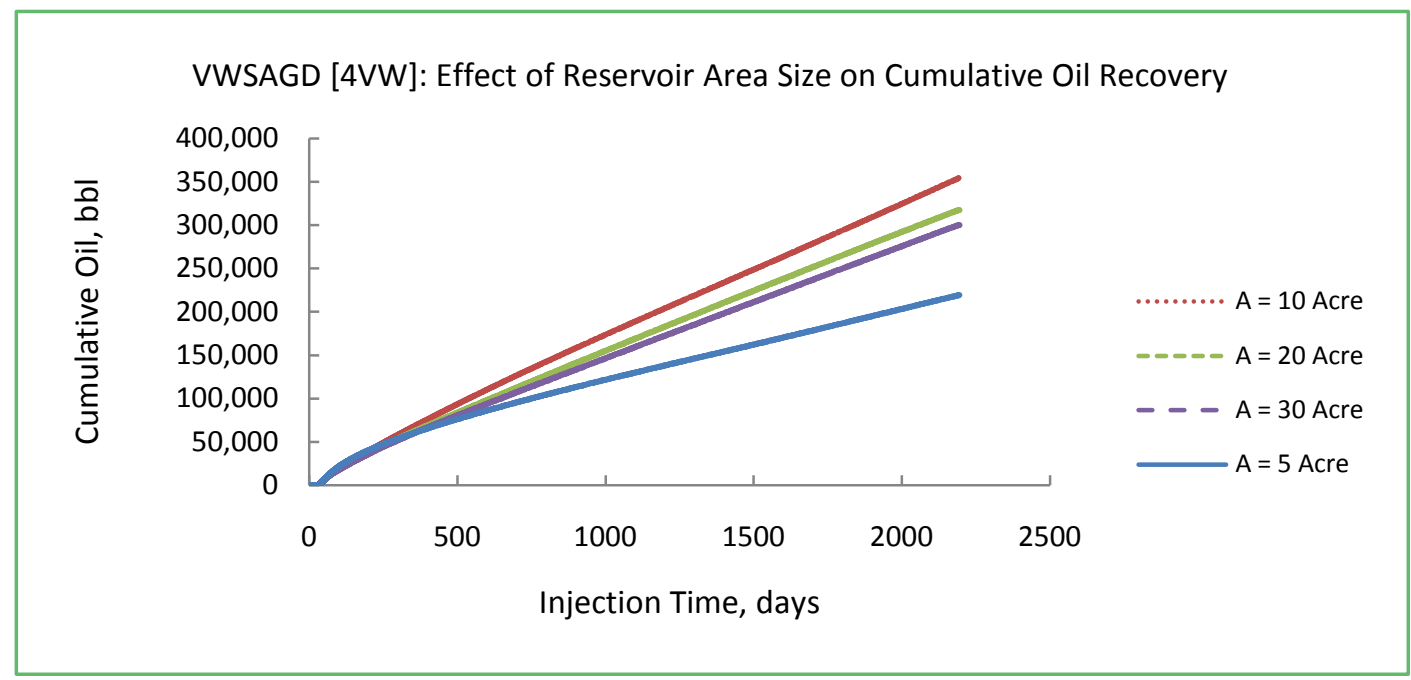

Figure 18. Total cumulative oil recovery from 4 vertical wells for VWSAGD process. 


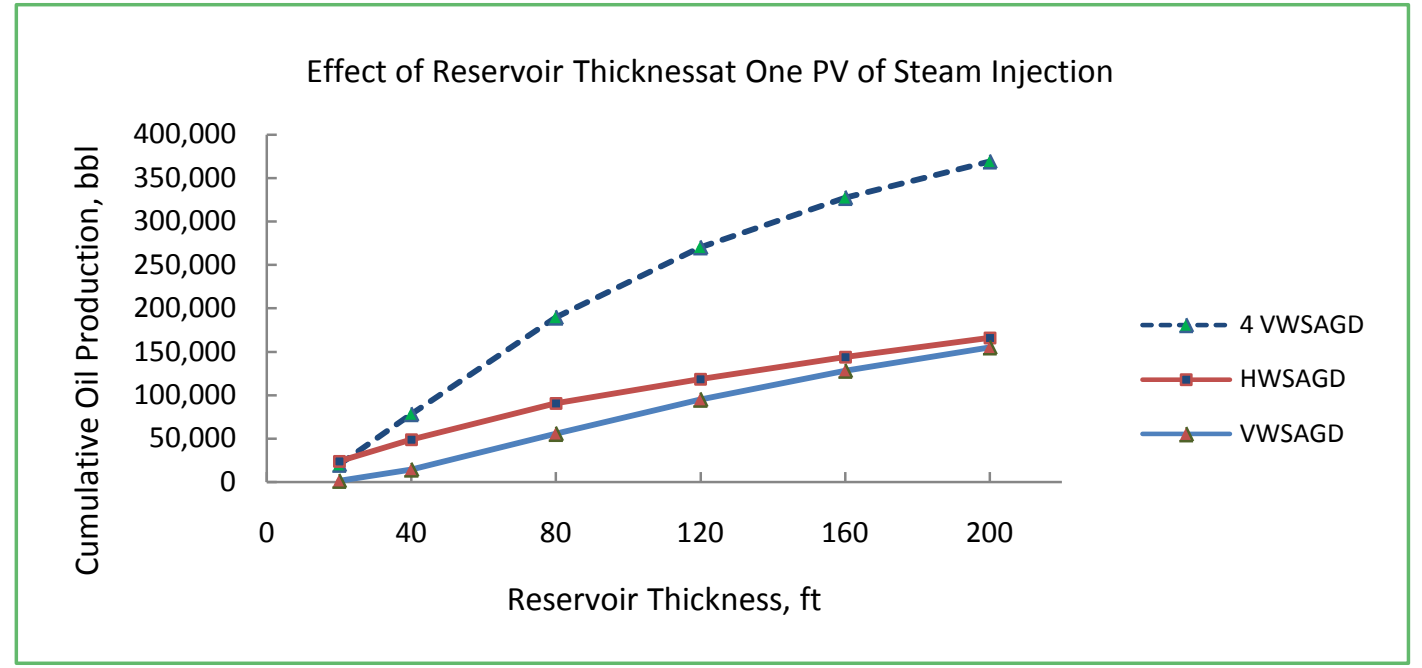

Figure 19. Effect of reservoir thickness on oil recovery for HWSAGD and VWSAGD processes.

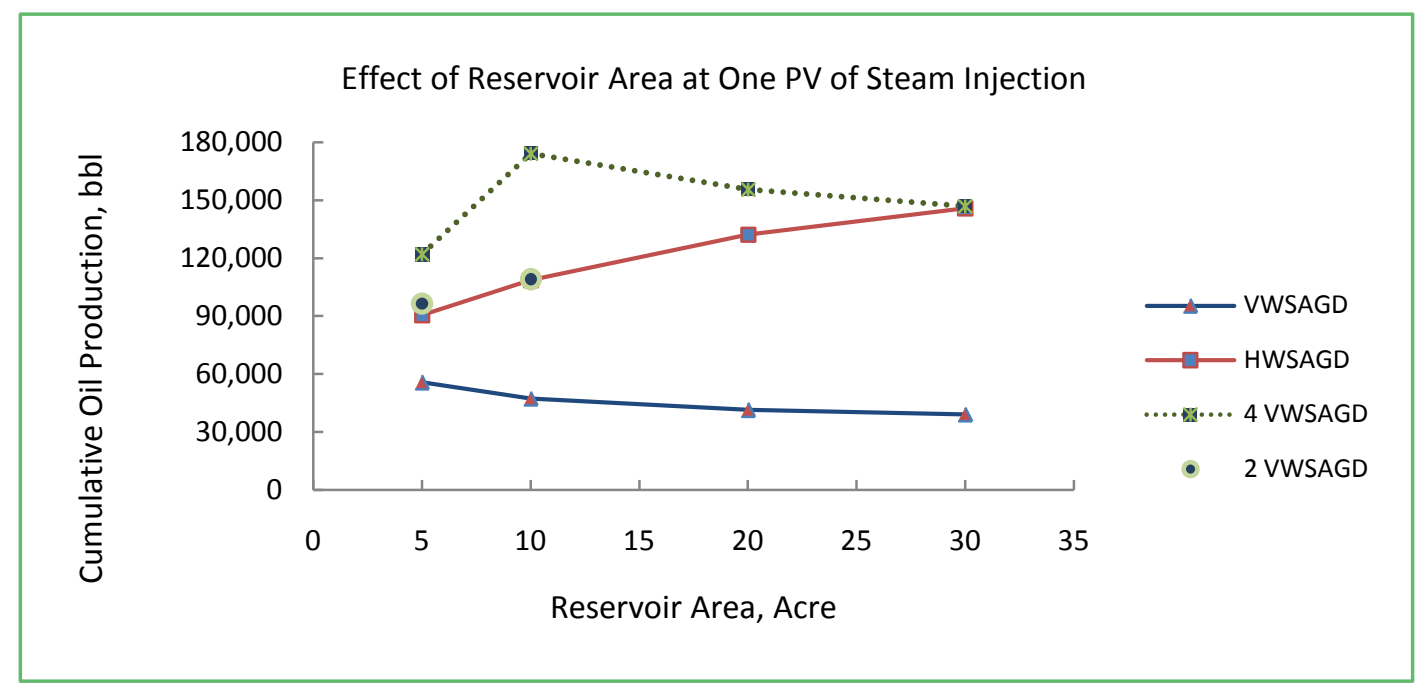

Figure 20. Effect of reservoir area on oil recovery for HWSAGD and VWSAGD process.

increases, the four vertical well SAGD and the horizontal well SAGD gave the same recovery when the area was equal to 30 acres. The results in Figure 20 also showed that the optimum area, which gave the highest recovery for four vertical well SAGD, was 10 acres.

\section{Conclusions}

Based on this research study, we can conclude the following:

1) A new process (VWSAGD) for steam assisted gravity drainage utilizing vertical wells has been presented. The process was optimized and tested. This new process has shown very promising results.

2) As the reservoir thickness increases, the new process is more suitable and gives better results.

3) As the reservoir vertical permeability decreases, the vertical well SAGD is more shown better oil recovery. 


\section{Acknowledgements}

The authors gratefully acknowledge the unlimited financial support of the Faculty of Graduate Studies and Research at the University of Regina.

\section{References}

[1] Butler, R.M. (1991) Thermal Recovery of Oil and Bitumen. Prentice Hall Publishing Company, New Jersey.

[2] Butler, R.M. and Stephens, D.J. (1981) The Gravity Drainage on Steam Heated Heavy Oil to Parallel Horizontal Wells. Journal of Canadian Petroleum Technology, 20, 90-96. https://doi.org/10.2118/81-02-07

[3] Sawhney, G.S., Liebe, H. and Butler, R.M. (1995) Vertical Injection Wells for SAGD: A Practical Option or Not. Journal of Canadian Petroleum Technology, 34, 9 p. https://doi.org/10.2118/95-01-06

[4] Butler, R.M. (1985) A New Approach to the Modelling of Steam Assisted Gravity Drainage. Journal of Canadian Petroleum Technology, 24, $11 \mathrm{p}$. https://doi.org/10.2118/85-03-01

[5] Sugianto, S. and Butler, R.M. (1990) The Production of Conventional Heavy Oil Reservoirs with Bottom Water Using Steam Assisted Gravity Drainage.

[6] Butler, R.M. (1998) SAGD Comes of AGE. Journal of Canadian Petroleum Technology, 37, 4 p. https://doi.org/10.2118/98-07-da

Submit or recommend next manuscript to SCIRP and we will provide best service for you:

Accepting pre-submission inquiries through Email, Facebook, LinkedIn, Twitter, etc. A wide selection of journals (inclusive of 9 subjects, more than 200 journals)

Providing 24-hour high-quality service

User-friendly online submission system

Fair and swift peer-review system

Efficient typesetting and proofreading procedure

Display of the result of downloads and visits, as well as the number of cited articles

Maximum dissemination of your research work

Submit your manuscript at: http://papersubmission.scirp.org/

Or contact eng@scirp.org 